IZADP No. 3585

Good Governance and Good Aid Allocation

Gil S. Epstein

Ira N. Gang

July 2008 


\title{
Good Governance and Good Aid Allocation
}

\author{
Gil S. Epstein \\ Bar-Ilan University, \\ CReAM and IZA \\ Ira N. Gang \\ Rutgers University \\ and IZA
}

Discussion Paper No. 3585

July 2008

IZA

P.O. Box 7240

53072 Bonn

Germany

Phone: $+49-228-3894-0$

Fax: +49-228-3894-180

E-mail: iza@iza.org

Any opinions expressed here are those of the author(s) and not those of IZA. Research published in this series may include views on policy, but the institute itself takes no institutional policy positions.

The Institute for the Study of Labor (IZA) in Bonn is a local and virtual international research center and a place of communication between science, politics and business. IZA is an independent nonprofit organization supported by Deutsche Post World Net. The center is associated with the University of Bonn and offers a stimulating research environment through its international network, workshops and conferences, data service, project support, research visits and doctoral program. IZA engages in (i) original and internationally competitive research in all fields of labor economics, (ii) development of policy concepts, and (iii) dissemination of research results and concepts to the interested public.

IZA Discussion Papers often represent preliminary work and are circulated to encourage discussion. Citation of such a paper should account for its provisional character. A revised version may be available directly from the author. 
IZA Discussion Paper No. 3585

July 2008

\section{ABSTRACT \\ Good Governance and Good Aid Allocation}

We model the aid allocation decision where the donor government has announced that good governance is the criterion for receiving aid. Potential recipients must compete for the aid funds. The structure of the competition is important to the donor in terms of achieving good governance, and to the recipients in terms of what they receive. The leaders of potential recipient countries look at aid availability through this contest as part of the competing objectives they face - some good, some not good. The donor country prefers a contest under which the aid will only go to one country while the leaders of the receiving countries prefer that each country obtains the proportion of aid relative to its governance quality. If poverty reduction is an independent goal as well, a poverty trap may be created. With good governance as a criterion, donors may work through both bilateral and multilateral agencies.

JEL Classification: $\quad$ O10, O19, F35, O11, C23, O47, E21, E22

Keywords: foreign aid, governance, decentralization, rent seeking

Corresponding author:

Ira N. Gang

Economics Department

Rutgers University

75 Hamilton Street

New Brunswick, NJ 08901-1248

USA.

E-mail: gang@economics.rutgers.edu 


\section{Good Governance and Good Aid Allocation}

\section{Introduction}

While not universally embraced, a stylized fact of development policy has become that "good governance” is a necessary pre-requisite for foreign aid to be effective in terms of raising a nation's rate of growth, lowering poverty, and generally achieving development goals. Allocating aid on the basis of potential recipient countries with good governance is a "win-win" situation: aid is given to where it will have an impact and objective criteria can be established, minimizing the necessity for detailed bureaucratic planning, disbursement, and oversight. Giving aid to only those with good governance reduces the need for many levels of checks and allows the aid allocation decision to be made by those closest to the needs.

The good governance criterion in recent aid discussions arose during the rather lively debate on the effectiveness of foreign aid. ${ }^{1}$ At the heart of the debate is the claim that aid is only effective in appropriate policy environment; otherwise, it will be diverted by corrupt bureaucracies and self-interested governments. In spite of the dispute over the empirical particulars of various research, the definition of better policies, and how to measure good governance, there is acceptance amongst many researchers that better policies and governance result in more effective aid. This implies that development assistance should be conditioned on attaining defined levels of good governance, usually measured by reaching certain values for a variety of indices on good governance. ${ }^{2}$ The introduction into the US debate of the Millennium

\footnotetext{
1 This debate is nicely summarized in Lahiri and Michaelowa, 2006. See also McGillivray, Feeny, Hermes and Lensink, 2005, for a review and analysis of the empirical work surrounding this debate. Heckelman and Knack, 2005, make the argument that aid retards economic liberalization.

${ }^{2}$ For example, the Millennium Challenge Corporation uses 16 indices grouped into three categories: ruling justly (civil liberties, political rights, voice and accountability, government effectiveness, rule of law, control of corruption), economic freedom (cost of starting a business, inflation, fiscal policy, days to start a business, trade policy, regulatory quality rating) and investing in people (public expenditure on health, immunization, public expenditure on primary education, girls' primary completion rate). Last accessed, July 26, 2006. http://www.mca.gov/countries/selection/short_descriptions.shtml.
} 
Challenge Account and the establishment of the Millennium Challenge Corporation arose in this environment. $^{3}$

The acknowledgement that good governance is important to aid effectiveness and the implementation of aid allocation policy based on it does not remove self-interested bureaucrats or corruption from the picture. This paper assumes agents respond to a number of influences, including self-interest and the desire to perform well at their jobs, though these may pull them in different directions. A donor desires to allocate aid on the basis of good governance. To keep the modeling reasonable, we do not discuss self-interested agents on the donor's side. The agents of the donor aid agency's agents carry out their government's wishes to implement the good governance criterion for aid allocation. What we particularly examine on the donor's side is the design and implications for governance of the contest among potential recipients to obtain aid. For the potential recipients, however, we look at the role and permanence of their leaders in these contests.

We model the aid allocation decision where the donor government has announced that good governance is the criterion for receiving aid. Potential recipients must compete for aid funds. The structure of the competition, we shall see, is important to the donor in terms of achieving good governance, and to the recipients in terms of what they receive. Potential recipients look at aid as part of the competing objectives they face - some good, some not so good. The governments, represented by their leaders, are the presumed beneficiaries of bad governance. Those implementing policies are explicit rent-seekers who consider aid as part of the total "package" available to them.

Donor agencies have limited resources and have to set priorities and decide on aid allocations. We examine and compare two contest structures that the donor may consider. In the first structure, the donor gives aid to the country that invests the most effort in quality governance. In the second, aid is divided proportionally according to the investment made by different countries in quality governance. We find the donor country prefers the system under which the aid will only go to one country while the leaders of the receiving countries prefer that each country obtains the proportion of aid relative to its governance quality. We also separate

3 See U.S. Agency for International Development, 2004. See Mavrotas and Villanger, 2006, for an alternative characterization of this process. 
the desire of the donor for good governance from the desire for poverty reduction, a consequence of which may be the development of a poverty trap. Recipient behavior may affect outcomes and, indeed, implementation can backfire in a multi-objective setting. In order to continue to receive transfers based on poverty a potential recipient government may deliberately allocate funds away from the poorest so as not to better their position.

In Section 2, which constitutes the bulk of the paper, we present our model and our major results. Section 3 examines the possibility of a poverty trap. Section 4 takes up another implementation of the model, the role of NGOs. Section 5 concludes.

\section{The Model}

Consider the case where there exist $m$ countries each wanting to obtain aid from the same donor. We assume that aid, $A$, is not determined endogenously; the donor has a fixed level of funds, $A$, to give out as aid. For example, the US Congress could determine the aid budget in light of other budgetary items. An aid agency, such as USAID might then decide how the aid budget should be divided among potential recipients.

Each potential recipient country has a leader who benefits from receiving aid. Note that the marginal benefit each leader receives may vary over countries as each country/leader may have different objectives or abilities in obtaining utility from the aid it receives. In order to simplify our model we assume that each leader benefits differentially from aid received, and the marginal benefit from each aid dollar is constant in each country but differs among countries. Denote by $n_{i}$ the marginal benefit the leader of country $i$ can receive from a dollar of aid. It is not clear which of the leaders had more to gain; that is whether $n_{i}$ is greater or smaller than $n_{j}$ for all $j \neq i$. One can think of winning aid in probabilistic terms. The probability that country/leader $i$ wins the contest and receives aid is equal to $P r_{i}$. The benefit country/leader i expects to receive in this competition equals $\operatorname{Pr}_{i} A n_{i}$. One can also look at $P r_{i}$ as the proportion of total aid that country/leader i receives. In the two scenarios we present below, one naturally lends itself to a discussion in terms of the probability of winning aid, while the intuition for the other is better when thinking about the proportion of aid obtained. ${ }^{4}$

\footnotetext{
${ }^{4}$ Proportions and probabilities are isomorphic only under risk neutrality, which is assumed.
} 
The donor decides potential recipient countries must invest in quality governance in order to receive aid. The more one invests the higher its chance of receiving aid. Obviously, good governance is only one of many goals that the donor may define, but we keep with the recent literature in presuming that the donor chooses governance as the goal on the assumption that this ensures proper spending of aid funds. We denote by $x_{i}$ the amount of effort and investment in quality governance by a country/leader $i$. Effort, $x_{i}$, can be seen as the number or quality of changes in a country ( $x_{i}$ can be a measurable index of change). The investments made by all countries/leaders, $x_{i}$, determine the proportion of the aid obtained (or the probability of winning the contest). 5 , 6

We assume that investment in quality governance is costly to a leader. Investment in quality governance decreases the power of a leader; for example, a leader will have less control and as a result obtain fewer and smaller bribes. Therefore, a leader sees investment in quality governance as a reduction in his utility. However, investment in quality governance is part of a contest among countries to obtain aid. While the utility of a leader declines as more investment in good governance takes place, the potential for receiving aid funds raises the leader's expected utility.

We consider two cases:

(a) All of the aid goes to one country. Here we assume that the donor country gives aid to the country that invests the most effort in quality governance.

(b) Aid is divided proportionally according to the investment made by each of the leaders of the different countries in quality governance.

To simplify we assume that quality governance has a fixed marginal cost of unity for each unit of quality governance invested by the leader. Thus, the expected net payoff (surplus) for the risk neutral leader of a country is

${ }^{5}$ Just because one invests in good governance doesn't mean that it is obtained. Moreover, some countries may obtain good governance with smaller investments than other countries. Noting these two caveats, we assume that investment in good governance is synonymous with obtaining good governance.

${ }^{6}$ There exists different type of competitions over aid. On decentralization of contest over aid see Epstein and Gang (2006) 


$$
E\left(w_{i}\right)=\operatorname{Pr}_{i} A n_{i}-x_{i} \forall i=1,2, \ldots, m .
$$

We assume that the proportion of the aid obtained in the contest (or the probability of winning the contest) satisfies the following conditions: (1) The sum of the proportions of the aid obtained equals one, $\sum_{i=1}^{m} \operatorname{Pr}_{i}=1$. (2) As country/leader $i$ increases its effort in quality governance, it obtains a higher proportion of the donor's aid, $\frac{\partial \mathrm{Pr}_{i}}{\partial x_{i}}>0$. (3) As the leader of country $j$, the opponent of the leader of country $i$, increases efforts in quality governance, the proportion of the aid that the leader of country $i$ obtains decreases, $\frac{\partial \mathrm{Pr}_{i}}{\partial x_{j}}<0$. Finally, (4) the marginal increase in the proportion of the aid obtained from the contest decreases with investment in quality governance, $\frac{\partial^{2} \mathrm{Pr}_{i}}{\partial x_{i}{ }^{2}}<0$ (this inequality ensures that the second order conditions for maximization are satisfied). ${ }^{7}$

The leaders of the countries engage in a contest over quality governance in order to obtain aid from the donor country. We assume a Nash equilibrium outcome. Each country determines the level of its quality governance $x_{i}$ so that its expected payoff, $E\left(w_{i}\right) \forall i=1,2, . ., m$, is maximized. The first order condition for maximization is given by

$$
\frac{\partial E\left(w_{i}\right)}{\partial x_{i}}=\frac{\partial \operatorname{Pr}_{i}}{\partial x_{i}} A n_{i}-1=0
$$

Equation (2) is satisfied if and only if

$$
\frac{\partial \mathrm{Pr}_{i}}{\partial x_{i}}=\frac{1}{A n_{i}}
$$

Thus, given the proportion of aid going to a country has decreasing marginal benefit with respect to quality governance, we obtain that the country with the higher marginal benefit from a dollar of aid will invest more effort in quality governance. For example, if the leader of country 1 has

${ }^{7}$ The function $\operatorname{Pr}_{\mathrm{i}}$ (.) is usually referred to as a contest success function (CSF). The functional forms of the CSF's commonly assumed in the literature satisfy these assumptions (see Nitzan, 1994). 
the higher marginal benefit from a dollar of aid when compared to the leader of country 2, $n_{1}>n_{2}$, then country 1 will determine its effort in quality governance, $x_{1}$, such that the marginal proportions are $\frac{\partial \operatorname{Pr}_{1}}{\partial x_{1}}<\frac{\partial \mathrm{Pr}_{2}}{\partial x_{2}}$, in order to increase its proportion of the aid received. In other words, the leader who has the highest marginal benefit from winning the contest will invest the highest amount of effort in quality governance.

To simplify and without loss of generality assume that,

$$
n_{1} \geq n_{2}>n_{3} \geq \ldots \geq n_{m}
$$

This assumption simply states that there are leaders from at least two countries who have higher marginal benefit compared to leaders of all other countries.

\subsection{Aid given to one country only}

We now describe the situation where the donor gives all the aid to only one country. We assume the extreme situation that all aid goes to the country that has undertaken the greatest investment in quality governance. In other words, the leader who invests in the highest level of quality governance will receive the entire donor's aid allocation, A. The contest success function in this case is the all-pay auction where the country that invests the highest amount in quality governance wins all of the aid; however, those that do not win cannot revert to lower quality governance. While some part of the quality governance is reversible, not all of it is reversible. To simplify we assume that none of the investment in quality governance is reversible.

The contest success function (CSF), the probability of winning aid under the all-pay auction where only one country obtains aid is given by ${ }^{8}$

\footnotetext{
${ }^{8}$ Under this scenario thinking in terms of the probability of winning the contest enhances our intuition.
} 


$$
\operatorname{Pr}_{i}=\left\{\begin{array}{c}
1 \quad \text { if } \quad x_{i}>x_{j} \forall i \neq j \\
\frac{1}{k} \quad \text { if i ties for the highbid with }(k-1) \text { others } . \\
0 \quad \text { if } \quad x_{j}>x_{i} \forall i \neq j
\end{array}\right.
$$

It can be verified that there exists a unique symmetric Nash equilibrium as well as a continuum of asymmetric Nash equilibria. In any equilibrium, countries 3 through m invest zero effort in quality governance activities with probability one (see Baye, Kovenock, and de Vries, 1993), so that only the two countries whose leaders have the highest marginal benefit from aid will participate.

Result 1: In the contest under which aid goes only to one country, only the two countries that have the highest marginal benefit from the aid will invest in quality governance.

If the donor is deciding on a strategy by which to allocate aid, this contest is good only if there are a small number of countries competing. From the m countries only two participate in the contest and thus only two will invest effort in quality governance.

We conduct our further analysis assuming two leaders of two countries, leader 1 and leader 2. Without loss of generality, assume that the marginal benefit of leader 1 from aid is greater than that of the leader of country $2, n_{1}>n_{2}$. It is clear, therefore, that leader 1 is able to make larger investments in quality governance than leader 2 . However, it is not clear how much each leader will invest in equilibrium. We can thus see investments in quality governance as bids of the leaders. It is a standard result that there are no pure strategy equilibria in all-pay auctions (Hillman and Riley (1989), Ellingsen (1991) and Baye, Kovenock and de Vries (1993)). It is also a standard result that there is no equilibrium in pure strategies in all-pay auctions. Suppose leader 2 bids $0<x_{2} \leq n_{2}$. Then the first leaders optimal response is $x_{1}=x_{2}+\varepsilon<A n_{1}$ (i.e., marginally higher than $x_{2}$ ). But then $x_{2}>0$ cannot be an optimal response to $x_{1}=x_{2}+\varepsilon$. Also, it is obvious that $x_{1}=x_{2}=0$ cannot be an equilibrium. Hence, there is no equilibrium in pure strategies. There is a unique equilibrium in mixed strategies given by the following cumulative 
distribution functions (see Hillman and Riley (1989), Ellingsen (1991) and Baye, Kovenock, and de Vries, 1993)), $G_{1}\left(x_{1}\right)=\frac{x_{1}}{n_{2}}$ for $x_{1} \in\left[0, n_{2}\right)$ and $G_{2}\left(x_{2}\right)=1-\frac{n_{2}}{n_{1}}+\frac{x_{2}}{A n_{1}}$ for $x_{2} \in\left[0, n_{2}\right)$. The equilibrium c.d.f's show that leader 1 bids uniformly on $\left[0, n_{2}\right]$, while leader 2 puts a probability mass equal to $\left(1-n_{2} / n_{1}\right)$ on $x_{2}=0$. The expected quality governance investments are equal to $E\left(x_{1}\right)=\int_{0}^{n_{2}} x_{1} d G_{1}\left(x_{1}\right)=\frac{A n_{2}}{2}$ and $E\left(x_{2}\right)=\int_{0}^{n_{1}} x_{2} d G_{2}\left(x_{2}\right)=\frac{A n_{2}^{2}}{2 n_{1}}$. Note that in the all-pay auction we can think of the designation "leader" as probabilistic - i.e., the stronger player is more likely to win the contest.

Based on these studies, we can obtain the equilibrium expected investment in quality governance, equilibrium probabilities and expected payoffs. In the case of only two leaders the probability of winning becomes

$$
\operatorname{Pr}_{i}=\left\{\begin{array}{c}
1 \quad \text { if } \quad x_{i}>x_{j} \\
0.5 \text { if } x_{i}=x_{j} \\
0 \quad \text { if } \quad x_{j}>x_{i}
\end{array}\right.
$$

The expected investment in quality governance for each country is given by

$$
E\left(x_{1}^{*}\right)=A \frac{n_{2}}{2} \text { and } E\left(x_{2}^{*}\right)=A \frac{n_{2}^{2}}{2 n_{1}} \text {. }
$$

The equilibrium probability of winning the aid for each country equals

$$
\operatorname{Pr}_{1}^{*}=\frac{2 n_{1}-n_{2}}{2 n_{1}} \text { and } \operatorname{Pr}_{2}^{*}=\frac{n_{2}}{2 n_{1}}
$$

The expected equilibrium payoff for each country equals

$$
E\left(w_{1}^{*}\right)=A\left(n_{1}-n_{2}\right) \text { and } E\left(w_{2}^{*}\right)=0 \text {. }
$$

In equilibrium, the total amount of quality governance carried out by both countries (assuming one can add the components) equals

$$
E\left(X^{*}\right)=E\left(x_{i}^{*}+x_{j}^{*}\right)=A \frac{n_{2}^{2}+n_{2} n_{1}}{2 n_{1}}=A \frac{n_{2}\left(n_{2}+n_{1}\right)}{2 n_{1}} .
$$


In the literature this measure is called rent dissipation.

\subsubsection{Identical marginal benefits from aid}

Let us consider the case where both leaders have the same marginal benefit from a dollar of aid,

$$
n_{1}=n_{2}=n
$$

The investment of each in quality governance equals,

$$
E\left(x_{1}^{*}\right)=A \frac{n}{2}=E\left(x_{2}^{*}\right)
$$

The probability of winning aid by each of the countries equals one-half, the expected payoff for each leader is zero and the total invested in quality governance by both countries together equals the total value of aid to the leaders of the countries,

$$
\operatorname{Pr}_{1}^{*}=\operatorname{Pr}_{2}^{*}=\frac{1}{2}, E\left(w_{1}^{*}\right)=E\left(w_{2}^{*}\right)=0 \text { and } X^{*}=A n
$$

\subsection{Aid proportionate to the quality governance of each country}

Here we consider the case where the leaders of the countries compete with one another in a contest in which no one wins all the aid. In the general case there are m countries competing against one another. Later in this paper we compare our two cases with each other. In the case where only one country gets all the aid we saw above that only the leaders of the two countries with the highest marginal benefit from a dollar of aid will compete. In the case we discuss below, the number of competing countries has a strong impact on the expected payoffs and on the total amount of resources invested in activities to increase quality governance. It can be shown that as the number of countries increases both the expected amount of resources invested in quality governance and expected payoffs of the leaders of the countries may increase or decrease. This will depend on the relative levels of the marginal benefit of aid of competing leaders (Baye, Kovenock, and de Vries, 1993, Che, and Gale, 1998 and Epstein and Nitzan, 2006a, 2006b). As a result of this, and as we wish to compare our results in this type of situation 
to the one presented above, we restrict our analysis to the case where only two leaders compete for aid.

Each country under this contest for aid will receive an amount of funds proportionate to the amount of resources invested in quality governance. We assume that the contest is characterized by the Tullock (1980) contest success function (see also Lockard and Tullock, 2001),

$$
\operatorname{Pr}_{i}=\frac{x_{i}}{x_{j}+x_{i}} \text { for } \forall j \neq i
$$

This function states that each country receives aid proportional to its investment in quality governance relative to the investment made in quality governance by the competing country.

The expected net payoff (surplus) for the risk neutral leader of country $i$ is thus given by

$$
E\left(w_{i}\right)=\operatorname{Pr}_{i} A n_{i}-x_{i}=\frac{x_{i}}{x_{i}+x_{j}} A n_{i}-x_{i} \quad \forall i \neq j, i, j=1,2 .
$$

The first order condition, as stated in equation (2), that ensures the leaders of the countries maximize their expected payoff, is given by

$$
\frac{\partial E\left(w_{i}\right)}{\partial x_{i}}=\frac{x_{j}}{\left(x_{i}+x_{j}\right)^{2}} A n_{i}-1=0 \quad \forall i, j=1,2 i \neq j .
$$

Denote by $x_{i}^{*} \forall i, j=1,2 i \neq j$ the Nash equilibrium outcome of the contest. Solving (16) for both leaders using a Nash equilibrium, we obtain that the level of quality governance activities of each country participating equals

$$
x_{1}^{*}=A \frac{n_{1}^{2} n_{2}}{\left(n_{1}+n_{2}\right)^{2}} \text { and } x_{2}^{*}=A \frac{n_{1} n_{2}^{2}}{\left(n_{1}+n_{2}\right)^{2}} \text {. }
$$

Therefore, in the Nash equilibrium, the proportion of aid obtained by each of the countries in this contest ${ }^{9}$ equals

\footnotetext{
${ }^{9}$ Under this scenario our intuition is enhanced by thinking in terms of the proportion of the rents obtained from the contest.
} 


$$
\operatorname{Pr}_{1}^{*}=\frac{n_{1}}{n_{1}+n_{2}} \quad \text { and } \quad \operatorname{Pr}_{2}^{*}=1-\operatorname{Pr}_{1}^{*}=\frac{n_{2}}{n_{1}+n_{2}}
$$

From (17) and (18) we obtain that the expected equilibrium payoff for each leader equals

$$
E\left(w_{1}^{*}\right)=A \frac{n_{1}^{3}}{\left(n_{1}+n_{2}\right)^{2}} \quad \text { and } \quad E\left(w_{2}^{*}\right)=A \frac{n_{2}^{3}}{\left(n_{1}+n_{2}\right)^{2}} .
$$

And, finally, assuming we can add up the amounts of effort invested in quality governance of the countries, we can calculate the total amount of effort invested by both countries together in quality governance. In the literature this measure is called rent dissipation. In our contest it tells us how much effort the leaders in the countries have invested in quality governance in order to increase the proportion of aid obtained from the donor country.

We denote this total effort invested (rent dissipation) in quality governance in equilibrium by $X^{*}$,

$$
X^{*}=x_{i}^{*}+x_{j}^{*}=A \frac{n_{1} n_{2}}{n_{i}+n_{j}} .
$$

\subsubsection{Identical marginal benefits from aid}

In the case where the leaders of the countries are symmetric in terms of their marginal benefit from aid, i.e., $n_{1}=n_{2}=n$ (as in (11)), we obtain that the level of investment in quality governance for each of the countries will be identical and equal to,

$$
x_{1}^{*}=x_{2}^{*}=\frac{n}{4} A .
$$

The Nash equilibrium proportion of the aid obtained by each of the countries will be equal to one-half,

$$
\operatorname{Pr}_{1}^{*}=\operatorname{Pr}_{2}^{*}=\frac{1}{2}
$$


The expected equilibrium payoff to each leader equals,

$$
E\left(w_{1}^{*}\right)=E\left(w_{2}^{*}\right)=\frac{n}{4} A,
$$

and, finally, the total effort invested in quality governance (rent dissipation) in equilibrium equals,

$$
X^{*}=\frac{n}{2} A .
$$

\subsection{Comparing proportional aid and aid to one country}

We now wish to compare these two types of contests both from the perspective of the donor and from that of the leaders of the recipient countries. The donor is concerned with the level (the quantity and intensity) of the quality of governance in potential recipient countries. It wishes to find a contest that will maximize the amount of quality governance for a given level of aid. The recipient leaders wish to have a contest that will maximize their expected net payoffs. Let us, therefore, compare both systems and see which is better from the perspective of the donor and of the leaders of the recipient countries.

\subsubsection{Identical marginal benefit from aid}

Let us first compare the two situations when both leaders have the same marginal benefit from aid, $n_{1}=n_{2}=n$.

Under the contest where aid goes only to one country we obtained from (12) and (13),

$$
E\left(x_{1}^{*}\right)=E\left(x_{2}^{*}\right)=A \frac{n}{2}, \operatorname{Pr}_{1}^{*}=\operatorname{Pr}_{2}^{*}=\frac{1}{2}, E\left(w_{1}^{*}\right)=E\left(w_{2}^{*}\right)=0 \text { and } X^{*}=A n \text {. }
$$

Under a contest that each obtains a proportional amount of aid relative to their investment in quality governance we obtained from (21)-(24),

$$
x_{1}^{*}=x_{2}^{*}=A \frac{n}{4}, E\left(w_{1}^{*}\right)=E\left(w_{2}^{*}\right)=A \frac{n}{4}, \operatorname{Pr}_{1}^{*}=\operatorname{Pr}_{2}^{*}=\frac{1}{2}, X^{*}=A \frac{n}{2} .
$$


It is clear, therefore, that in both cases the probability/proportion of aid received by each country is identical to fifty percent. Each country when all the aid goes to one country invests more resources in quality governance while each of the leaders of the countries have a higher expected payoff under the proportional system where each country receives aid proportionate to their investment effort in quality governance. The more one invests the higher is the chance of receiving aid. The more fungible are non-aid funds - the easier it is to change domestic patterns of government expenditure - the easier it is for the leader of a country to turn around the governance system and embark on the path towards higher quality. Therefore, requiring that a country have higher quality governance helps channel resources appropriately. Since the total amount of aid is fixed, the situation that maximizes the quality of governance increases the flexibility of non-aid funds. It is important to notice that even if only one country is receiving aid both countries are investing in quality governance so the return to the aid contest, even though only one country is receiving aid, is from the two countries competing for the funds.

Since the donor wishes to maximize quality governance and the leaders of the countries wish to maximize expected payoffs we obtain,

Result 2: In the case of an identical marginal benefit from each dollar of aid for the leaders of the country, the donor country prefers the system under which aid will all go to only one country while the leaders of the receiving countries prefer that each country obtains the proportion of aid relative to its governance quality.

\subsubsection{Marginal benefit from aid is not identical}

Now let is consider the case where the marginal benefit to the leaders from aid are not identical and that leader 1 has a higher marginal benefit than leader 2, $n_{1}>n_{2}$.

In the case where all aid goes to one country, for the country that invests in the highest level of quality governance, we obtained from (7) - (10) that expected investment in quality governance, the probability of winning the aid, the expected net payoff of the leaders and the total investment in quality governance equal, 


$$
E\left(x_{1}^{*}\right)=A \frac{n_{2}}{2}, E\left(x_{2}^{*}\right)=A \frac{n_{2}^{2}}{2 n_{1}} ; \quad \operatorname{Pr}_{1}^{*}=\frac{2 n_{1}-n_{2}}{2 n_{1}}, \operatorname{Pr}_{2}^{*}=\frac{n_{2}}{2 n_{1}}
$$

$$
E\left(w_{1}^{*}\right)=A\left(n_{1}-n_{2}\right), E\left(w_{2}^{*}\right)=0 ; \quad \text { and, } E\left(X^{*}\right)=A \frac{n_{2}\left(n_{2}+n_{1}\right)}{2 n_{1}} .
$$

On the other hand, under the contest where each country receives aid in proportion to its investment in quality governance, we obtained from (17) - (20) that investment in quality governance, the probability of winning the aid, the expected net payoff of the leaders and the total investment in quality governance equals,

$$
x_{1}^{*}=A \frac{n_{1}^{2} n_{2}}{\left(n_{1}+n_{2}\right)^{2}}, x_{2}^{*}=A \frac{n_{1} n_{2}^{2}}{\left(n_{1}+n_{2}\right)^{2}} \quad ; \quad \operatorname{Pr}_{1}^{*}=\frac{n_{1}}{n_{1}+n_{2}}, \quad \operatorname{Pr}_{2}^{*}=\frac{n_{2}}{n_{1}+n_{2}} ;
$$

$$
E\left(w_{1}^{*}\right)=A \frac{n_{1}^{3}}{\left(n_{1}+n_{2}\right)^{2}} ; \quad E\left(w_{2}^{*}\right)=A \frac{n_{2}{ }^{3}}{\left(n_{1}+n_{2}\right)^{2}} \quad \text { and } X^{*}=x_{i}^{*}+x_{j}^{*}=A \frac{n_{1} n_{2}}{n_{i}+n_{j}}
$$

\section{The Donor}

Let us start by analyzing the relationship between the two contests from the donor's perspective. In order to receive aid the donor determines that the receiving countries must invest in quality governance.

The total amount of expenditure on quality governance invested in the contest is higher under the proportional division of aid rather than the case where all aid goes to one country if

$$
A \frac{n_{2} n_{1}}{n_{1}+n_{2}}>A \frac{n_{2}\left(n_{2}+n_{1}\right)}{2 n_{1}}
$$

Equation (29) holds if and only if

$$
n_{1}^{2}-2 n_{1} n_{2}-n_{2}>0 \text {. }
$$

From (30) we may conclude that the total amount invested in quality governance is higher under 
the proportional system than the system in which only one country receives the aid if

$$
n_{1}>n_{2}(1+\sqrt{2})
$$

Since, by assumption, $n_{1} \geq n_{2}$, the result tells us that in order for the proportional system to be better off for the donor country the marginal benefit of a dollar of aid to the leader of country 1 has to be sufficiently larger than that of the other leader (more specifically it has to be more than twice as large). We summarize this result in the following proposition,

Result 3: If the ratio between the marginal benefit to the leaders of the countries is sufficiently large, i.e., $\frac{n_{1}}{n_{2}}>1+\sqrt{2}$, then the donor country will prefer the proportional system under which the countries obtain aid proportional to their investment in quality governance over the system in which all the aid goes to the country that invested the most in quality governance.

\section{The leaders of the countries}

In order to analyze the preferences of the leaders of the countries who wish to obtain aid we must compare their expected payoffs under both systems. Remember that we assumed, without loss of generality, that leader 1 has at least as large a stake as leader $2\left(n_{1} \geq n_{2}\right)$. The leaders of the countries prefer the aid system that generates for them the maximum expected equilibrium payoff, $E\left(w_{i}^{*}\right)$. Under the proportional aid system, the expected equilibrium net payoff for leader 2 (the leader with the lower marginal benefit from aid) equals $E\left(w_{2}^{*}\right)=A \frac{n_{2}{ }^{3}}{\left(n_{1}+n_{2}\right)^{2}}$, while the expected equilibrium under the system where aid goes to only one country equals zero, $E\left(w_{2}^{*}\right)=0$. Therefore it is clear that, 
Result 4: The leader with the lower marginal benefit from aid always prefers the proportional system under which each country receives aid proportional to the amount invested in quality governance.

For the leader who has the higher marginal benefit from aid the expected equilibrium net payoff under the proportional system equals $E\left(w_{1}^{*}\right)=A \frac{n_{1}^{3}}{\left(n_{1}+n_{2}\right)^{2}}$, while the expected equilibrium net payoff under the system where aid goes only to one country equals $E\left(w_{1}^{*}\right)=A\left(n_{1}-n_{2}\right)$. The expected payoff for leader 1 under the proportional system is greater than that obtained under the other system if

$$
\frac{n_{1}^{3}}{\left(n_{1}+n_{2}\right)^{2}}>n_{1}-n_{2}
$$

Equation (32) holds if and only if

$$
n_{1}^{2}-2 n_{1} n_{2}-n_{2}<0 .
$$

From equation (33) we may conclude that the proportional system benefits the leader with the higher marginal benefit if

$$
0<n_{1}<n_{2}(1+\sqrt{2})
$$

In other words,

Result 5: The leader with the higher marginal benefit prefers the proportional system if the difference between the leaders' marginal benefit is not sufficiently large, $\frac{n_{1}}{n_{2}}<1+\sqrt{2}$. 
The donor and the leader of the country with the higher marginal benefit from aid have conflicting preferences. However, the donor and the leader with the lower marginal benefit from aid have the same preferences with regard to the type of contest to hold.

\section{Poverty trap}

Now assume that the criteria for obtaining aid is not only how much you invest in quality governance but also the country's poverty level. Let $d_{i}$ be a parameter capturing how bad off the country is in terms of poverty. We can think of $d_{i}$ as the number of poor or a more formal measure of poverty, where increasing $d_{i}$ indicates greater poverty. In order to compare our results to the ones presented above we restrict this analysis to the decentralized division of aid under which countries obtain aid in proportion to the level of investment in quality governance (as well as the poverty level). We do not analyze this in the system where aid all goes to one country as then we have to determine the criteria under which the "best" wins. This will give us many different possibilities and for each we would get different results. Thus, in order for us to be able to compare the results obtained earlier we confine ourselves to the decentralized method under which each receives a proportion of the aid allocation. Moreover, in order to add emphasis to our results we will consider the case where both countries have the same marginal benefit from aid, $n_{1}=n_{2}=n$. The reason here, again, is convenience and simplicity in comparing the results.

Let the contest success function, the proportion of aid received by country $i$, be equal to,

$$
\operatorname{Pr}_{i}=\frac{d_{i} X_{i}}{d_{j} X_{j}+d_{i} x_{i}} \text { for } \forall j \neq i
$$

Each country under this contest for aid will receive funds proportional to investment in quality governance and the level of poverty. The donor allocates aid based on the level of poverty (more poverty, more aid), making the probability of receiving aid increase with greater poverty. This contest success function is a variant of the Tullock (1980) contest success function (see also Epstein, 2000). 
The leader of each country invests in quality governance, $x_{i}$, and decides whether to invest in poverty reduction (lowering $d_{i}$ ) or not (either allowing poverty to stay the same or increase). The expected net payoff of the leader of country $i$ is given by

$$
E\left(w_{i}\right)=\frac{d_{i} x_{i}}{d_{i} x_{i}+d_{j} x_{j}} A n-x_{i}-d_{j} \quad \forall i \neq j, i, j=1,2 .
$$

Solving the first order conditions for both players we obtain that the optimal investment in quality governance and in poverty (that is, having poverty increased) equals,

$$
x_{1}^{*}=x_{2}^{*}=d_{1}^{*}=d_{2}^{*}=\frac{n}{4},
$$

and the probability of winning and the total expenditure on quality governance equal,

$$
X^{*}=\frac{n}{2} \quad \text { and } \operatorname{Pr}_{1}^{*}=\operatorname{Pr}_{2}^{*}=\frac{1}{2} \text {. }
$$

As we can see from this example the results in terms of the donor country are identical to those we obtained when there was not an option to increase the proportion of aid received based on the poverty level (see (21)-(23)). In both cases the leaders of the countries invest the same amount of resources. Thus, both leaders receive in the two cases the same proportion of aid, invest the same amount of resources in quality governance and at the same time spend effort and resources in a way that poverty increases (of course, one measure of good governance could be poverty reduction). In other words, such a policy by the donor country will increase poverty.

Result 6: If the donor introduces a condition under which the portion of aid received by a country is a function of the poverty of a country as well as good governance, then this induces the country to invest in ways that increase poverty while at the same time increase resources invested in quality governance. Such a system creates a poverty trap causing the leaders of the countries to invest in order to raise the poverty level so as to obtain a higher proportion of the available aid. 


\section{NGOs verses donor countries}

Now assume that countries that have a small amount of resources to donate will choose to do so directly to one country. On the other hand, NGOs may have many more available funds and with returns to scale would be more able to give their resources to many countries. Assuming the donor and the NGO have the same goals we may conclude,

Result 7: In the case of $m>2$ countries competing for donor resources, the donor takes part of the resources and lets two of the countries compete for it in the way that the one with the highest quality of governance receives all the funding. It gives the rest of the funding to NGOS who divide the aid proportionate to the amount of resources invested by each of the countries.

\section{Conclusion}

Aid provides recipient governments opportunities to shift resources from expenditures intended by donors into other activities. Presuming the donors' desires are honorable and helpful, fungibility can undermine the effectiveness of aid. The empirical literature has not been able to provide a robust measure of the degree of aid fungibility (Gang and Khan, 1990, 1999; Feyzioglu, Swaroop, and Zhu, 1998; McGillivray and Morrissey, 2001). Never-the-less for many years- at least since the introduction of structural adjustment aid in the 1980s - aid policy has assumed near $100 \%$ fungibility. The recent discussion on good governance is no different; since aid effectively supports the entire public sector, establishing good governance is a pre-requisite for the effective use of aid.

There is, of course, an extensive discussion of many issues surrounding the concept of good governance, for example, what it means, how it can be implemented, and at what rate does good governance translate into good development outcomes. The presumption by academics and aid practitioners is that good governance cannot hurt, and should therefore be pursued as a criterion on which to allocate aid.

This is where we start. We discuss and compare choices facing the donor in deciding how to allocate aid when good governance is the established criterion. The donor is interested in 
achieving the highest aggregate level of good governance, that is, the sum of efforts made by all potential recipients. The donor wants maximum rent dissipation. One of the contests we have the donor consider is winner-takes-all, where potential recipients compete to establish good governance but only one receives aid in the end. The second contest is where aid is divided proportionately among potential recipients based on their efforts to achieve good governance.

Recipients are not passive. They have objectives of their own; in particular, their leaders may have their own programs. What drives our model is the donors' desire for good governance and local leaders' desire for long-term gain. Our main result is that the recipient who is most effective in governance - and stands to benefit the most from development assistance - has interests opposite to those of the donor. This brings in a role for multilateral agencies and nongovernment organizations (NGOs) who may choose a different contest than the donor. In doing so rent dissipation can be increased. We also discuss the addition of a second criterion for aid allocation - the desire of the donor to directly address poverty. A consequence of these multiobjective goals may be the development of a poverty trap: in order to continue to receive transfers based on poverty a potential recipient government may deliberately allocate funds away from the poorest so as not to better their position. Incentives often work in non-obvious ways. 


\section{References}

Baye, Michael R., Dan Kovenock, and Casper G. de Vries. 1993. Rigging the lobbying process: an application of the all-pay auction. American Economic Review 83(1):289294.

Che, Yeon. and Ian Gale. 1998. Caps on political lobbying. American Economic Review 88(3):643-651.

Ellingsen, Tore. 1991. Strategic buyers and the social cost of monopoly. American Economic Review 81(3):648-657.

Epstein, Gil S. 2000. Personal productivity and the likelihood of electoral success of political candidates. European Journal of Political Economy 16(1): 95-111.

Epstein Gil S. and Ira N. Gang. 2006. Contests, NGOs and decentralizing aid. Review of Development Economics 10(2):285-206.

Epstein Gil S. and Shmuel Nitzan, 2006a. Effort and performance in public policy contests. Journal of Public Economic Theory 8(2):265-282.

Epstein Gil S. and Shmuel Nitzan. 2006b. Reduced prizes and increased effort in contests. Social Choice and Welfare 26(3), 447-453.

Feyzioglu, T., Swaroop, V. and M. Zhu, 1998, 'A Panel Data Analysis of the Fungibility of Foreign Aid’, World Bank Economic Review, Vol.12, No.1, pp. 29-58.

Gang, Ira N. and Haider Ali Khan 1990, “Foreign aid, taxes, and public investment,” Journal of Development Economics, 34:1-2, pp. 355-369.

Gang, Ira N. and Haider Ali Khan, 1999, 'Foreign Aid and Fiscal Behaviour in a Bounded Rationality Model: Different Policy Regimes’, Empirical Economics, Vol.24, No.1, pp.121-34.

Heckelman, Jac and Stephen Knack. 2005. Foreign aid and market-liberalizing reform. World Bank Policy Research Working Paper 3557, April.

Hillman, Arye L. and John G. Riley. 1989. Politically contestable rents and transfers. Economics and Politics 1(1):17-39.

Lahiri, Sajal and Katharina Michaelowa. 2006. Political economy of aid. Review of Development Economics 10(2): 177-178.

Lockard, Alan A; Tullock, Gordon, eds. 2001. Efficient rent-seeking, chronicle of an intellectual quagmire. Boston: Kluwer Academic Publishers.

Mavrotas, George and Espen Villanger. 2006. Multilateral aid agencies and strategic donor behaviour. Discussion Paper 2006/02. UNU-WIDER, Helsinki, Finland.

McGillivray Mark and Oliver Morrissey (2001) "Aid Illusion and Public Sector Fiscal Behaviour", Journal of Development Studies, Vol. 37, No. 6, 118-136.

McGillivray, Mark, Simon Feeny, Niels Hermes and Robert Lensink. 2005. It works; it doesn't; it can, but that depends.” Research Paper 2005/54. UNU-WIDER, Helsinki, Finland. 
Nitzan, Shmuel. 1994. Modelling rent-seeking contests. European Journal of Political Economy 10(1): 41-60 (also appears in Lockard and Tullock (2001)).

Tullock, Gordon. 1980. Efficient rent-seeking. In Toward a theory of the rent-seeking society, edited by J.M. Buchanan, R.D. Tollison, and G. Tullock, 97-112. College Station, TX: Texas A. and M. University Press.

U.S. Agency for International Development. 2004. U.S. foreign aid meeting the challenges of the twenty-first century bureau for policy and program coordination. http://www.usaid.gov/policy/pdabz3221.pdf. Last accessed July 26, 2006. 